\title{
Female Athletes And Performance-Enhancer Usage
}

\author{
Barbara K. Fralinger,(E-mail: fralinge21@hotmail.com), Keystone College \\ Genevieve Pinto-Zipp, Seton Hall University \\ Valerie Olson, Seton Hall University \\ Susan Simpkins, Seton Hall University
}

\begin{abstract}
The purpose of this study was to develop a knowledge base on factors associated with performance-enhancer usage among female athletes at the high school level in order to identify markers for a future prevention-education program. The study used a pretest-only, betweensubjects Likert Scale survey to rank the importance of internal and external pressures that may lead to performance-enhancer usage among this population. Subjects included 122 female athletes from top-ranked sport programs at $7 \mathrm{New}$ Jersey high schools. Descriptive and quantitative statistics were used to analyze the data at a $p \leq .05$ significance level. The Chi Square Test of Homogeneity, Spearman Correlation Coefficient, Kruskal-Wallis One-Way ANOVA, and Scheffé Post-Hoc Test were used to analyze associations between the nine survey issues and five levels of importance. Results indicated that subjects rated the pressure to win and self-induced competitive pressures as the two most important factors in leading to performance-enhancer usage. Chi-Square results showed significant differences in the level of importance for each of the nine issues presented, while the Spearman Correlation revealed several correlations among certain issues. The Kruskal-Wallis One-Way ANOVA showed significant differences in ranks when data were grouped by school and sport. Post-Hoc analysis supported findings of the Kruskal-Wallis One-Way ANOVA. This study provided descriptive and quantitative data that added to the existing research. The findings may be used by health educators and athletic coaches for performance-enhancer prevention-education programs.
\end{abstract}

\section{FEMALE ATHLETES AND PERFORMANCE-ENHANCER USAGE}

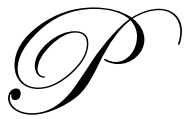

erformance-enhancer abuse is growing rapidly among young women (Donatelle, 2002; NIDA, 2000). The explosion of professional female sports is giving young women of all ages more opportunity to compete at higher levels. This increased opportunity is leading to greater pressure to win, which may be contributing to performance-enhancer usage among female athletes as young as 12 years of age (Metzl et al., 2001; Yesalis \& Bahrke, 2000). Because of the growing number of young women using performanceenhancers, it is important for health educators to understand what these substances are, how they work, the potential side effects, and the factors contributing to usage among this population.

Performance-enhancers are ergogenic drugs used to provide an additional physical "edge" for an athlete engaging in competition (Donatelle, 2002). This class of drugs (i.e., anabolic steroids, amphetamines, cocaine, etc.) is known to produce harmful physiological and psychological effects, including loss of hair, sterility, outbursts of rage, liver damage and heart complications (Donatelle, 2002; Insel \& Roth, 2000). Despite the dangerous side effects associated with performance-enhancer usage, athletes continue to use a variety of ergogenic aids.

Amphetamines, cocaine, caffeine, Human Growth Hormone, certain over-the-counter nutritional substances that do not require FDA approval, and anabolic androgenic steroids (AAS), are used by many athletes to either increase energy level or gain muscle mass (Smith \& Perry, 1992; Millman \& Ross, 2003). Although legal usage of steroids and other performance-enhancers in the U.S.A. is only permissible for medical purposes through physician prescription, many athletes are illegally obtaining and taking large dosages of these substances (Donatelle, 2002). 
Current research shows that female athletes across competitive levels are using performance-enhancers to improve both their athletic performance and appearance (Metzl et al., 2001; Johnson, 1990; Pecci \& Lombardo, 2000). Specifically, these studies indicate that at the high school level, increasing numbers of female athletes are taking steroids and nutritional supplements (Luetkemeier et al., 1995; Tyler, Lauver, \& Zitans, 1991; Bahrke et al., 1998; Terney \& McLain, 1990), with prevalence rates in grades 11 and 12 approaching levels equal to collegiate athletes

(Metzl et al., 2001). While these and other studies present statistical information on the rate of performance-enhancer usage among female athletes at various ages and competitive levels, there is no information on the potential factors (i.e., peer pressure, pressure to win, coaching pressure, etc.) leading to usage among this population.

\section{PURPOSE OF THE STUDY}

In order to make informed decisions about the use of steroids and other performance-enhancing drugs, female athletes need to recognize the factors leading to usage and the dangerous side effects that may occur. While most health educators teach adolescents about the risks associated with steroid/ performance-enhancers, educators must also address the reasons underlying usage. To date, no published studies have examined the psychological or emotional factors (i.e., peer pressure, pressure to win, coaching pressure, etc.) underlying the reported increase in performance-enhancer usage among young women athletes. Identifying these factors would establish markers that could be used to develop a prevention-education program. Therefore, the purpose of this study was to identify factors associated with performance-enhancer usage among high school female athletes. It is anticipated that the information obtained would help health educators and coaches to design educational programs that can assist young women in making informed decisions about performance-enhancer use.

\section{METHODS}

The study used a pretest-only, between-subjects Likert Scale survey design to rank the importance of some of the internal and external pressures that may lead to performance-enhancer usage among female athletes at the high school level. The Seton Hall University Institutional Review Board approved the research proposal for this study.

\section{Subjects}

All athletes in the target population at the selected New Jersey high schools who met the inclusion criteria were invited to participate in the study. Top-ranked sport teams were identified from the sports editors' poll of the Newark Star Ledger and Courier Post newspapers. The researcher met with the coaches and team members prior to a practice session to collect the consent forms and distribute the survey. Athletes who obtained parental consent and wanted to participate completed the survey. Confidentiality and other rights of athletes consenting to participate were protected in accordance with IRB requirements. A total of 122 female athletes participated in the study.

\section{Study Sites}

Potential study sites were identified from New Jersey newspapers. Rankings of high school sport teams were displayed in the Newark Star Ledger and Courier Post newspapers. The researcher personally telephoned coaches and athletic directors of these teams at each high school site to discuss the study rationale and preliminary study procedures. Coaches interested in participating or receiving further information were sent a letter by e-mail that specifically explained the study design and procedures. Coaches were also provided with copies of the informed consent and the survey instrument (see Appendix A), if desired. The participating seven high schools were from the northern, central, and southern regions of the state of New Jersey. 


\section{Procedures}

The survey was administered prior to practice sessions to the high school female athletes who obtained parental consent and chose to participate in the study. Content validity of the survey instrument was obtained from a pilot study (Fralinger, 2006) conducted with a panel of six coaches of women's sports considered to be experts in their field.

\section{Data Analysis Methods}

Data obtained from each of the 122 completed surveys were coded and entered into the Statistical Package for Social Sciences (SPSS 9.0) computer software program.

\section{Independent Variables.}

The nine independent variables were the issues presented in the survey: (1) pressure to win; (2) peer pressure by teammates; (3) pressure by the school to win; (4) self-induced competitive pressures; (5) conscious or unconscious pressure by coaches; (6) issues relating to body image; (7) societal pressures; (8) competitive level; (9) curiosity/experimentation. The survey was constructed so that each of these independent variables had a numeric Likert Scale rating of 1-5.

Dependent Variables.

The five dependent variables were the following ratings of importance in the Likert Scale: (1) very important; (2) important; (3) moderately important; (4) unimportant; (5) most unimportant.

\section{Statistical Testing}

Data analysis included both descriptive and quantitative statistics. Statistical testing was performed to analyze the relationship between the independent and dependent variables. Since the data were not normally distributed, nonparametric statistics were used. An alpha level of $\mathrm{p} \leq .05$ was considered significant (Hinkle, Wiersma, \& Jurs, 1998).

\section{RESULTS}

\section{Demographic Characteristics Of The Participating High Schools}

Demographic characteristics were obtained for descriptive information about the participating high schools. Grade level, enrollment, competitive level, student ethnicity, grade standards, and student economic level for each school are presented in Table I. The demographic data was gathered to provide information that may be useful when interpreting results derived from the statistical analyses. 
Table I

Demographic Characteristics of the Participating High Schools

\begin{tabular}{|c|c|c|c|c|c|c|}
\hline School & Grades & Enrollment & $\begin{array}{l}\text { Competitive } \\
\text { Level* }\end{array}$ & $\begin{array}{c}\text { Student } \\
\text { Ethnicity*** }\end{array}$ & $\begin{array}{c}\text { Grade } \\
\text { Standards**** }\end{array}$ & $\begin{array}{c}\text { Student } \\
\text { Economic } \\
\text { Level***** }\end{array}$ \\
\hline A: North NJ & $9-12$ & 769 & Group II & $\begin{array}{l}\mathrm{AA}=<1 \% \\
\mathrm{AI}=0 \% \\
\mathrm{As}=4 \% \\
\mathrm{H}=3 \% \\
\mathrm{~W}=93 \%\end{array}$ & $\begin{aligned} \mathrm{LA} & =100 \% \\
\mathrm{M} & =98 \%\end{aligned}$ & $1 \%$ \\
\hline B: Central NJ & $9-12$ & 3009 & Group IV & $\begin{array}{l}\mathrm{AA}=6 \% \\
\mathrm{AI}=0 \% \\
\mathrm{As}=4 \% \\
\mathrm{H}=1 \% \\
\mathrm{~W}=88 \%\end{array}$ & $\begin{array}{l}\mathrm{LA}=97 \% \\
\mathrm{M}=87 \%\end{array}$ & $5 \%$ \\
\hline C: Central NJ & $9-12$ & 1446 & Group III & $\begin{array}{l}\mathrm{AA}=18 \% \\
\mathrm{AI}=<1 \% \\
\mathrm{As}=2 \% \\
\mathrm{H}=40 \% \\
\mathrm{~W}=40 \%\end{array}$ & $\begin{array}{l}\mathrm{LA}=79 \% \\
\mathrm{M}=59 \%\end{array}$ & $47 \%$ \\
\hline D: Central NJ & $9-12$ & 372 & Group I & $\begin{array}{l}\mathrm{AA}=3 \% \\
\mathrm{AI}=<1 \% \\
\mathrm{As}=1 \% \\
\mathrm{H}=9 \% \\
\mathrm{~W}=85 \%\end{array}$ & $\begin{array}{l}\mathrm{LA}=65 \% \\
\mathrm{M}=58 \%\end{array}$ & $0 \%$ \\
\hline E: South NJ & $9-12$ & 627 & Group II & $\begin{array}{l}\mathrm{AA}=9 \% \\
\mathrm{AI}=0 \% \\
\mathrm{As}=1 \% \\
\mathrm{H}=2 \% \\
\mathrm{~W}=88 \%\end{array}$ & $\begin{array}{l}\mathrm{LA}=93 \% \\
\mathrm{M}=85 \%\end{array}$ & $19 \%$ \\
\hline F: South NJ & $9-12$ & 1261 & Group III & $\begin{array}{l}\mathrm{AA}=26 \% \\
\mathrm{AI}=3 \% \\
\mathrm{As}=1 \% \\
\mathrm{H}=5 \% \\
\mathrm{~W}=65 \%\end{array}$ & $\begin{array}{l}\mathrm{LA}=75 \% \\
\mathrm{M}=60 \%\end{array}$ & $23 \%$ \\
\hline G: South NJ & $9-12$ & 1461 & Group IV & $\begin{array}{l}\mathrm{AA}=20 \% \\
\mathrm{AI}=1 \% \\
\mathrm{As}=1 \% \\
\mathrm{H}=11 \% \\
\mathrm{~W}=68 \%\end{array}$ & $\begin{array}{l}\mathrm{LA}=80 \% \\
\mathrm{M}=64 \%\end{array}$ & $32 \%$ \\
\hline
\end{tabular}

* Competitive levels are based on school population; higher population = higher group placement.

** $\quad \mathrm{AA}=$ African American; $\mathrm{AI}=$ American Indian; As = Asian; $\mathrm{H}=$ Hispanic $; \mathrm{W}=$ White

*** Percent of students meeting NJ grade standards in Language Arts (LA) and Math (M)

**** Percent of students receiving free or reduced-price lunch

\section{Descriptive Statistics Of Survey Data}

Descriptive statistics in the form of frequencies, means, medians, modes and standard deviations were performed to analyze the distribution of the survey data obtained on the nine issues rated by level of importance. Examination of descriptive statistics allowed the researcher to determine if the data was normally distributed and which statistical tests should be used for further analysis. Descriptive statistics are presented for the two most important issues determined from the data (see Figures 1 and 2). 
Frequencies were calculated to determine the mean score for each issue and also to see if the data were normally distributed. The mean score represents the average ranking given by respondents for each issue. The mean scores and frequency distributions were used to determine which issues were considered most important among respondents. The pressure to win can be thought of as the internal pressure felt by the athlete to win at all costs. Pressure to win (see Figure 1) yielded a mean score of 1.9, indicating an average ranking between "very important" and "important." The standard deviation was 1.11, signifying that responses for the pressure to win had little variability around the mean. In examining the frequency distribution, one can see that the data is not normally distributed for this issue. Out of 122 respondents, over half gave the pressure to win a ranking of 1 (very important) or 2 (important). Thus, the internal pressure felt by athletes to win at all costs was the issue ranked as most important in leading to performance-enhancer usage.

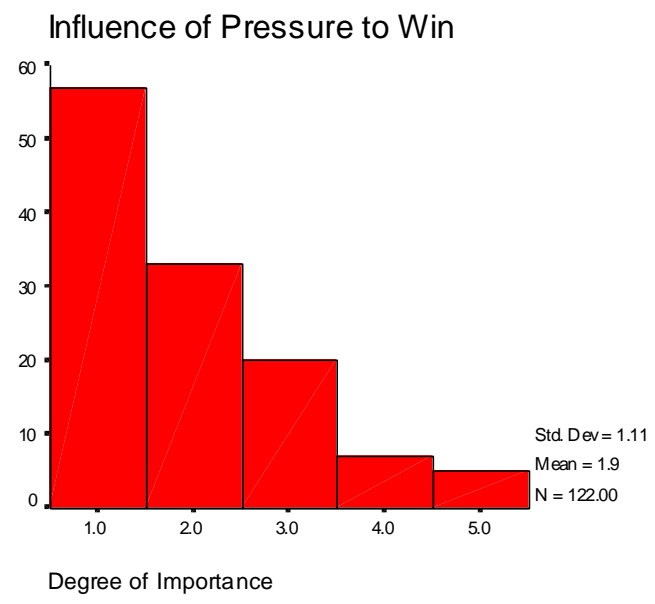

Figure 1.

The Pressure to Win Frequency Distribution. The pressure to win yielded a mean score of 1.9, indicating an average ranking of between "very important" and "important" by respondents. The standard deviation was 1.11, signifying little variability around the mean.

The second issue of significance was self-induced competitive pressure, which refers to the internal drive of the athlete or the pressures that the athlete puts on herself to win at all costs. This issue yielded a mean score of 2.0, indicating an average response ranking of "important." The standard deviation was 1.23, indicating little variability of responses around the mean. Therefore, most participants agreed that this issue was a potential precursor to engagement in performance-enhancer usage. As depicted in Figure 2, the data obtained for this issue were not normally distributed, as the majority of respondents ranked this issue "very important." 
Influence of Self-Induced

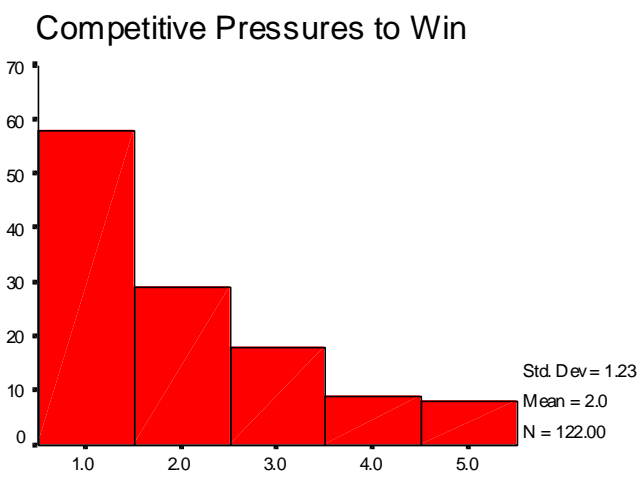

Degree of Importance

Figure 2

Self-Induced Competitive Pressures Frequency Distribution. Self-induced Competitive Pressure yielded a mean score of 2.0, indicating an average response ranking of "important." The standard deviation was 1.23 , indicating little variability of responses around the mean.

\section{DESCRIPTIVE ANALYSIS}

Table II demonstrates the mean, standard deviation, median, and mode of responses for each of the nine issues. This analysis allowed the researcher to determine which issues respondents ranked highest and lowest in terms importance in leading to performance-enhancer usage.

Table II

Distribution of Likert Scale Scores For Nine Issues Pertaining To Performance-Enhancer Usage

\begin{tabular}{|c|c|c|c|c|c|}
\hline Issue & $\begin{array}{l}\text { Number of } \\
\text { Respondents }\end{array}$ & $\begin{array}{c}\text { Mean } \\
\text { Deviation }\end{array}$ & Standard & Median & Mode \\
\hline Pressure to Win & 122 & 1.93 & 1.11 & 2 & 1 \\
\hline Self-Induced Competitive Pressures & 122 & 2.02 & 1.23 & 2 & 1 \\
\hline Competitive Level & 122 & 2.17 & 1.25 & 2 & 1 \\
\hline Conscious or Unconscious Pressure By Coaches & les 122 & 2.47 & 1.14 & 2 & 3 \\
\hline Issues Relating to Body Image & 122 & 2.69 & 1.26 & 3 & 3 \\
\hline Peer Pressure by Teammates & 122 & 2.92 & 1.08 & 3 & 3 \\
\hline Pressure by School & 122 & 3.10 & 1.10 & 3 & 3 \\
\hline Societal Pressures & 122 & 3.25 & 1.22 & 3 & 3 \\
\hline Curiosity/Experimentation & 122 & 3.34 & 1.26 & 3 & 3 \\
\hline
\end{tabular}

Participants generally showed limited variability in their responses to the 9 issues pertaining to performance-enhancer usage. Most participants ranked the issues "moderately important" to "very important," with a median score of 3 (moderately important) on the last five issues on Table II. The first four issues on Table II had a median score of 2, indicating a ranking of "important" for these issues. The mode, or most frequent score, for the pressure to win, self-induced competitive pressures, and competitive level was 1 (very important). However, for all other issues, the mode was 3 (moderately important). These results suggest that the pressure to win, self-induced competitive pressures, and competitive level were the issues most frequently scored "very important" in leading to performance-enhancer usage, while the remaining six issues were only considered "moderately important." In 
summary, the data were not normally distributed and suggest that the female athletes surveyed tended to have a high level of agreement regarding the level of importance of each of the nine issues presented. Therefore, nonparametric testing was used to further analyze the relationships between the nine issues and five levels of importance.

\section{Statistical Testing Analysis}

\section{Chi Square Test of Homogeneity.}

The data analysis using the Chi Square Test of Homogeneity suggested that there were significant differences $(\mathrm{p} \leq .05)$ between all nine issues and their corresponding level of importance. These results indicate that there was a significant difference noted in the level of importance for each of the nine issues presented to the female athletes, and that these differences were not due to chance.

\section{Spearman Correlation Coefficient.}

Using the Spearman analysis, significant relationships were found between the issues presented in Table III. All correlations were positive, indicating that as participants gave one issue a particular ranking, they also tended to give another issue the same ranking. For example, those athletes who gave societal issues a specific numeric rank (Spearman $\mathrm{r}=.516, \mathrm{p}=.000$ ) also tended to give issues relating to body image the same numeric rank. Another moderately strong correlation (Spearman $r=.284, \mathrm{p}=.001$ ), was found between the pressure to win and pressure by teammates.

Table III

Spearman Significant Correlations

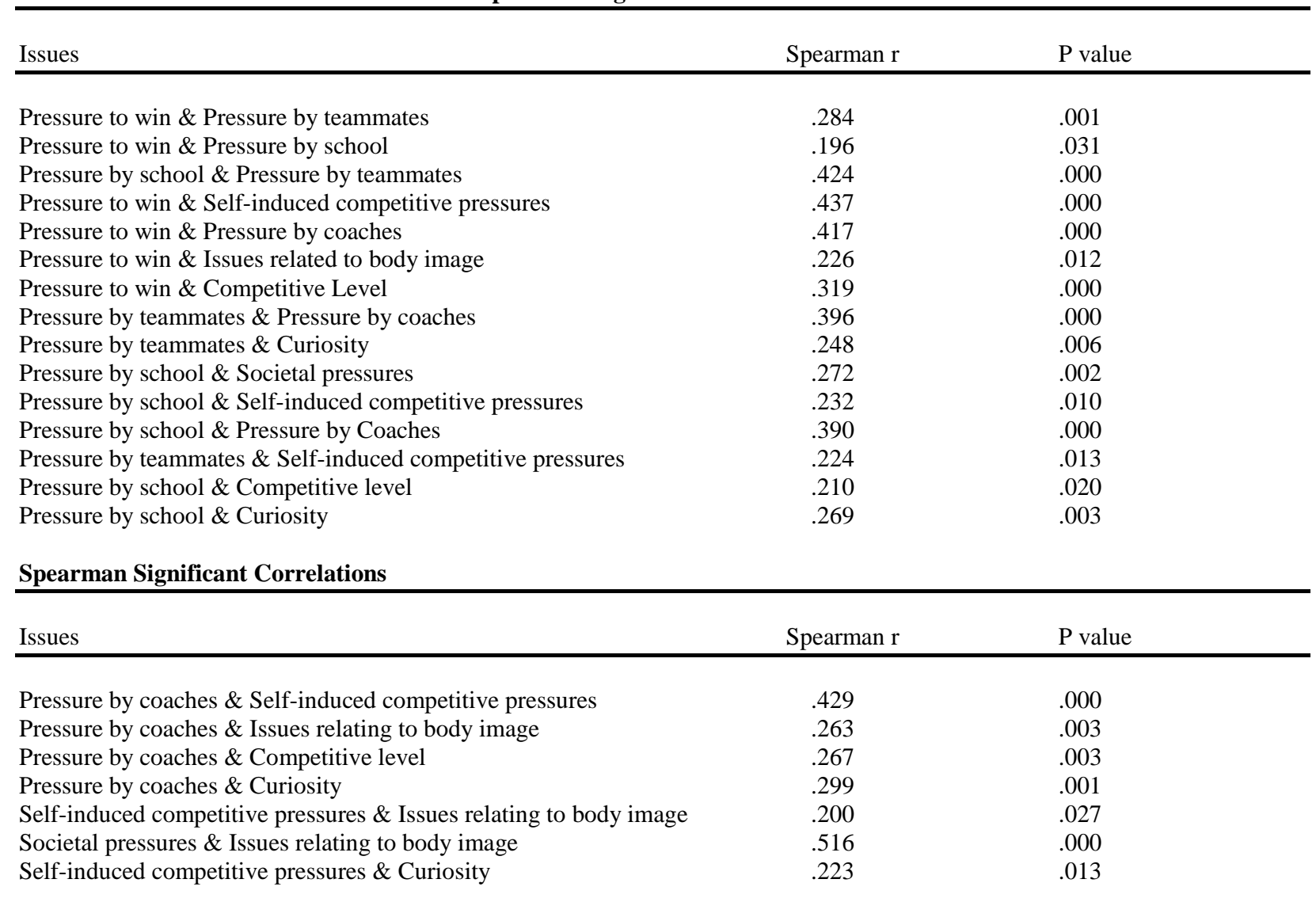


Kruskal-Wallis One-Way Analysis of Variance.

The Kruskal-Wallis Test was performed to determine the differences in responses when grouped by school and sport. Results of this test indicated that there were significant differences $(\mathrm{p} \leq .05)$ by school in responses for pressure by teammates, pressure by school, pressure by coaches, competitive level, and curiosity/experimentation. When grouped by sport, responses were significantly different for the issues of pressure by teammates, body image, and competitive level.

Post-hoc tests were performed to determine which means differed significantly after the ANOVA test was performed. Results of the Scheffé procedure reinforced the results obtained from the Kruskal- Wallis Test, as pressure by coaches was significant when grouped by school, while competitive level was significant when grouped by school and sport. The results of the post-hoc procedure further support what was found in the Kruskal-Wallis One-Way ANOVA, which was that the responses for importance of pressure by coaches and competitive level were significantly different for each school, and responses for competitive level were significantly different for each sport. This indicates that perhaps coaching style significantly influences an athlete's willingness to engage in performance-enhancer usage; and that athletes with the opportunity to compete at higher levels in various sports (i.e., tennis, swimming, basketball) possibly feel more pressure to engage in usage than those competing at lower levels (i.e., softball).

\section{DISCUSSION}

The primary purpose of this study was to identify some of the major issues that lead to the usage of performance-enhancers among female athletes at the high school level so that markers for a prevention-education program could be obtained. The findings of this study add to the existing knowledge base on performance-enhancer usage among athletes.

Our results indicate that of the nine issues athletes were asked to rank, the pressure to win and self-induced competitive pressures were considered the most important factors leading to performance-enhancer usage. Factors considered important were: Competitive level, pressure by coaches, body image concerns, and pressure by teammates. Pressure by the school, societal pressure, and curiosity were considered only moderately important.

These findings suggest that female athletes at the high school level may be engaging in performanceenhancer usage mostly due to the pressure to win and self-induced competitive pressures.

Usage of performance-enhancers appears to be due to a combination of internal and external determinants. According to the subjects surveyed, athletes feel a great pressure to win, which may be due to both self-induced competitive pressures and external pressures by coaches, the school, and teammates. Because top-ranked female athletes often have the self-motivation and desire to win, they may make the conscious decision to engage in usage of performance-enhancers with the hopes of maximizing athletic performance. In addition, if a female athlete has a poor perceived body image, she may engage in usage to obtain what is considered to be the "ideal" body type for success in her particular sport.

Using the Spearman analysis, significant correlations were found between many of the issues. Specifically, two of the issues shown to have the most significant correlations included:

Societal pressures \& issues relating to body image; and pressure to win $\&$ self-induced competitive pressures.

Results of the Kruskal-Wallis Test indicated that there were significant differences $(p \leq .05)$ by school in responses for pressure by teammates, pressure by school, pressure by coaches, competitive level, and curiosity/experimentation. When grouped by sport, responses were significantly different for the issues of pressure by teammates, body image, and competitive level. 
Demographic data of the school populations may explain results of the quantitative analyses performed. For example, athletes from School 1 and 2 (very competitive schools both academically and athletically) ranked self-induced competitive pressures as the most important factor leading to performance-enhancer usage. Students from both of these academic settings have a high economic level, and ranked higher than the NJ state average for academic standards in Language Arts and Math.

In addition, athletes from Schools 3, 4, and 6 ranked the pressure to win as the most important factor leading to performance-enhancer usage. These schools were all ranked in the top 1-2\% of their respective groups for their particular sport, indicating a possible increased response rate for pressure to win.

Schools with larger populations tend to be more competitive due to the increased number of athletes. Therefore it is not surprising that the athletes from the Group IV schools ranked competitive level as the most important factor.

Significant differences in responses existed for the issues of pressure by teammates, body image, and competitive level. Specifically, swimmers tended to rank body image and competitive level as the most important factors leading to performance-enhancer usage. These results are in agreement with those reported by Spence and Gauvin (1996), where female swimmers were found to consume weight-loss products for performance or appearance purposes.

Further, significant differences among responses by tennis and hockey players were noted as well. The pressure by teammates was ranked much higher in importance by hockey players than by tennis players. This could be attributed to the fact that tennis is primarily an individual sport, with possibly more self-induced competitive pressure than team pressure.

Rankings of importance for pressure by coaches and competitive level were significantly different for each school, and rankings for competitive level were significantly different for each school and sport. This suggests that perhaps coaching style significantly influences an athlete's willingness to engage in performance-enhancer usage; and that athletes with the opportunity to compete at higher levels in various sports (i.e., tennis, swimming, basketball) possibly feel more pressure to engage in usage than those competing at lower levels (i.e., softball).

Limitations of the study design and data analyses caution one against making definite conclusions. As with much survey-based research, potential limitations such as honesty of responses by participants and issues pertaining to external validity may exist.

Although neither the researcher nor the athletic coach was in the classroom at the time of survey completion, the participants may not have felt free to complete the survey honestly. Consequently, the responses reported may not truly reflect the athletes' perspective. Another possible limitation influencing responses is the Hawthorne effect, which involves participants responding differently than they normally would because they know they are part of a study.

Limitations also exist with external validity. Results from this study may not be generalizable outside New Jersey since the female athletes from this area may not be representative of female athletes everywhere.

\section{CONCLUSIONS}

In this study, it can be concluded that the pressure to win and self-induced competitive pressures were the two most important factors leading to engagement in performance-enhancer usage. According to the subjects surveyed, athletes feel a great pressure to win, which may be due to both self-induced competitive pressures and external pressures by coaches, the school, and teammates. Because top-ranked female athletes often have the selfmotivation and desire to win, they can make the conscious decision to engage in usage of performance-enhancers with the hopes of maximizing athletic performance. In addition, if a female athlete has a low perceived body image, she may engage in usage to obtain what is considered to be the "ideal" body type for success in her particular sport. 
Further, due to the internal and external pressures put on high school female athletes, performanceenhancer usage among this population is becoming more prominent. This study has substantiated the need for education on positive coping strategies for dealing with the pressures that young women face at this age. By educating these individuals about self-esteem and the dangers of performance-enhancer usage, we can encourage healthy behaviors.

\section{REFERENCES}

1. Bahrke, M.S., Yesalis, C.E., \& Brower, K.J. (1998). Anabolic-androgenic steroid abuse and performanceenhancing drugs among adolescents. Child and Adolescent Psychiatric Clinics of North America, Oct; 7(4), 821-838.

2. $\quad$ Donatelle, R.J. (2002). Access to Health ( $7^{\text {th }}$ ed.). San Francisco, CA: Pearson Education, Inc.

3. Fralinger, B. (March, 2006). Female Athletes and Performance-Enhancer Usage: Doctoral Dissertation. UMI Proquest Publications; Dissertation Abstracts. ISBN: 0-542-32603-5. Source: DAI-B, p. 4754.

4. Hinkle, D.E., Wiersma, W., \& Jurs, S.G. (1998). Applied Statistics for the Behavioral Sciences. Boston, MA: Houghton Mifflin Company.

5. Insel, P.M. \& Roth, W.T. (2000). Core Concepts in Health. Mayfield Publishing Company.

6. Johnson, M.D. (1990). Anabolic steroid use in adolescent athletes. Pediatric Clinics Of North America, Oct; 37(5), 1111-1123.

7. Luetkemeier, M.J., Bainbridge, C.N., Walker, J., Brown, D.B., \& Eisenman, P.A. (1995). Anabolicandrogenic steroids: prevalence, knowledge, and attitudes in junior and senior high school students. Journal of Health Education, 26(1), 4-10.

8. Metzl, J.D., Small, E., Levine, S.R., \& Gershel, J.C. (2001). Creatine use among young athletes. Pediatrics, Aug; 108(2), 421-425.

9. $\quad$ Millman, R.B. \& Ross, E.J. (2003). Steroid and nutritional supplement use in professional athletes. American Journal of Addiction, 12 Suppl, S48-54.

10. National Institute on Drug Abuse, “Anabolic Steroid Abuse,” NIDA Research Report Series (2000).

11. Pecci, M.A. \& Lombardo, J.A. (2000). Performance-enhancing supplements. Phys. Med. Rehabil. Clin. N. Am., 11(4), 949-960.

12. Smith, D.A., and Perry P.J. (1992). The efficacy of ergogenic agents in athletic competition part I: androgenic-anabolic steroids. Ann Pharmacother., Apr; 26(4), 520-8.

13. Spence, J.C. \& Gauvin, L. (1996). Drug and alcohol use by Canadian university athletes: A national survey. Journal of Drug Education, 26(3), 275-287.

14. Terney, R. \& McLain, L.G. (1990). The use of anabolic steroids in high school students. American Journal of Diseases of Children, 144(1), 99-103.

15. Tyler, J.V., Lauver, D.A., \& Zitans, M. (1991). Adolescent steroid use (report no. OEI-06-90- 01080). Washington, DC, The Department of Health and Human Services.

16. Yesalis, C.E. \& Bahrke, M.S. (2000). Doping among adolescent athletes. Baillieres Best Pract. Res. Clin. Endocrinol. Metab., Mar; 14(1), 25-35. 


\section{APPENDIX A}

\section{Female Athletes and Performance Enhancer Usage Student-Athlete Survey}

Directions: Please rate the following issues in terms of their importance in leading to steroid/ performanceenhancer usage among female athletes. Ratings are on a scale of 1 through 5:

- $\quad 1=$ very important

- $\quad 2=$ important

- $\quad 3=$ =moderately important

- $\quad 4=$ =unimportant

- $\quad 5=$ most unimportant

**Please circle the number that you feel is most appropriate for each issue.

\begin{tabular}{|c|c|c|c|c|c|}
\hline Issues Related to Performance-Enhancer Usage & \multicolumn{5}{|c|}{ Rating } \\
\hline The pressure to win & 1 & 2 & 3 & 4 & 5 \\
\hline Peer pressure by teammates & 1 & 2 & 3 & 4 & 5 \\
\hline Pressure by the school to win & 1 & 2 & 3 & 4 & 5 \\
\hline Self-induced competitive pressures & 1 & 2 & 3 & 4 & 5 \\
\hline Conscious or unconscious pressure by coaches & 1 & 2 & 3 & 4 & 5 \\
\hline Issues relating to body image & 1 & 2 & 3 & 4 & 5 \\
\hline Societal pressures (i.e. media, TV advertisements) & 1 & 2 & 3 & 4 & 5 \\
\hline Competitive Level (Group I, II, III, IV) & 1 & 2 & 3 & 4 & 5 \\
\hline Curiosity/Experimentation & 1 & 2 & 3 & 4 & 5 \\
\hline
\end{tabular}

Is there anything that you would add to the above list? If so, please list here.

\section{Additional Comments:}

**Would you like to receive results of all the data obtained from this survey?

If so, please call the Seton Hall Dept. of Graduate Medical Education at 973-275-2076 for information. 


\section{NOTES}

